The Eastern Librarian, Volume 23(1), 2012, ISSN: 1021-3643 (Print). Pages: 64-73. Available Online: http://www.banglajol.info/index.php/EL

\title{
THE JOURNAL OF POULTRY SCIENCE: AN ANALYSIS OF CITATION PATTERN
}

\author{
Md. Enamul Haque, PhD \\ Deputy Librarian, Bangladesh Agricultural University, Mymensingh 2202, Bangladesh
}

\begin{abstract}
This paper reports the results of the citation analysis of "The Journal of Poultry Science (JPS)." The major objectives of the study from the year2001 to 2010 are to find out the authorship and citation patterns of articles appeared in the JPS. The total 425 articles were published during the period. Overall 13012 citations featuring 425 contributors have been made. Among the citations, journal articles accounted for 84\%, books $8 \%$ and another's $8 \%$. The ratio of Author Self Citation to total citations is 1:16. The ratio of Journal Self Citation to total citations 1:58. It is also clear that majority of the documents 10102 (78\%) cited in these issues were published not more than 20 years ago.
\end{abstract}

DOI: http://dx.doi.org/10.3329/el.v23i1.12121

\section{KEYWORDS}

Citation Analysis, Poultry Science.

\section{INTRODUCTION}

The word Citation is well known to all literary persons or author(s). But citation analysis is not common to all. It makes particularly appropriate for journal analysis is the nature of the journal itself: an ongoing publication which is edited for quality and maintains some consistency of standards. Thus, the citations received by past articles can be used to predict the utility of present or future articles.

According to Hirade \& Dankhade (2002) citation analysis is one of the popular methods employed in recent days for the identification of core documents in various subject fields or for a particular specific community in a geographical

64 The Eastern Librarian-peer-reviewed journal in LIS since 1965 
proximity. In fact, citation study is one of the effective and indirect methods to understand the information requirements of users.

The significant of the scholarly communication media is now considered as the journals that play a primary role in the dissemination of information to the research scholars and the scientists in different fields who are doing research in day and night for inventing something new for the development of the society as well as the welfare of the human beings. Traditionally the quality of the journals is evaluated by the subject experts of that particular journal or by any scholarly academician. However based on the normative perspective of citation which views citing as a merit-granting process it is plausible to assume that the information value of a given publication is reflected by the frequency of citation obtained from other publications. (Weiping Yue, Concepctons and Wilson, 2004). On the other hand, "citation analysis is one of the popular methods employed in recent days for the identification of core documents in various subject fields or for a particular specific community in a geographical proximity. In fact, citation study is one of the effective and indirect methods to understand the information requirements of users." (Hirade and Dankhade, 2002). Again, Citation analysis measures how often items are cited in references, bibliographies, or indexing tools and compares their frequency of occurrence to collection holdings. (Locket, 1989).

There are different citation analyst have given different definition and how to evaluate the journal articles in different form of documents. "The journal citation indicators from the Institute of Scientific Information (ISI) have become popular measures in assessing journal performance, in particular the journal impact factor and the number of total citations. (Baskaram, Batcha, and Nagarjan, 2007).

Interrelationship among journal citation impact and four external factors that is journal characteristic, journal accessibility, journal visibility and journal internationality have been successfully explored, and the conceptual model of journal evaluation has been examined.

Therefore citation counts can be used as indicators or measurements of the level of quality, importance, influence or performance of individual publications or aggregations of publications, such as journals. (Wilson, 1999)

The goal of this study is to use citation analysis whether the BAU library is meeting the needs of information to the researchers of the Poultry Science department.

65 The Eastern Librarian-peer-reviewed journal in LIS since 1965 


\section{LITERATURE REVIEW}

Jan (2009), in his study found that 593 articles published in the journal of Library Trends from 1994 to 2007. Out of 13783 citations, articles accounted $44.04 \%$, books $44.51 \%$ and another's were proceedings, reviews and reports. Female contribution $(52.34 \%)$ accounts more than male contributions $(47.66 \%)$. Every issue published approx. 11 articles and each article has an average of 23.2 references and 3.1 e-citations.

Shokeen and Kaushik (2004) in their study found that among the citations, $24.54 \%$ were single author, $35.6 \%$ double, 21.24 Triple, $11.49 \%$ were four and rest five or more author. Out of 187 contributors, $4.28 \%$ college, $47.59 \%$ university and rest $48.13 \%$ were research institutes. Among the citations (1149), $81.11 \%$ articles and $13.84 \%$ were books. The ratio of author self citation to total citations were 1: $16.65 \&$ also journal self citation 1: 31.91 . Most of the cited documents were published not more than twenty years ago.

\section{SOURCE JOURNALS}

The Journal of Poultry Science (JPS) is an international journal published by the Japan Poultry Science Association from the year 1991 and onwards. The JPS covers all aspect of modern poultry science. The journal publishes original articles (full-length articles and research notes) and review articles written only in English language from 2001. At the beginning (1991) this journal as appeared as Japanese Journal of Poultry Science in Japanese language. From 2001 this journal was renamed The Journal of Poultry Science. Subjects include : Breeding \& Genetics, Nutrition \& Feeds, Physiology, Reproduction, Immunology, Environmental Science, Management \& Housing welfare, Processing \& Products, and Health in poultry. Submission of original articles to the journal is opened to all poultry researchers. The review articles are invited papers written by international outstanding researchers. Articles will be published in English, American style.

\section{SCOPE}

There are 13012 citations appended to 425 articles appeared in The Journal of Poultry Science from 2001 to 2010 have been analyzed. The journal is a quarterly published and covered vol. 38 to 47 for this study. The study mainly

66 The Eastern Librarian-peer-reviewed journal in LIS since 1965 
covered research articles, references appended at the end of the articles, authorship pattern of citations, percentage of contributors and journal self citation to total citations, publication years of the cited articles, citation forms for analysing purposes.

\section{OBJECTIVES OF THE STUDY}

The major objectives of the present study are :

i) to find out the authorship pattern;

ii) to find out the number of citations used;

iii) to identify the contributors organizations;

iv) to identify the forms of citations;

v) to prepare the list of contributing countries;

vi) to identify the ratio of Author Self Citation to the total number of citations;

vii) to identify the ratio of Journal Self Citation to the total number of citations and

viii) to identify the durability of literature.

\section{METHODOLOGY}

All the articles of volumes 38 to 47 (2001 - 2010) of the journal were scanned, checked, examined and tabulated manually in terms of authorship pattern, authors collaboration, institutional affiliation, local versus foreign contributors, ratio of author \& journal self citation s and durability of publications. Finally, the collected data was analysed for generating information. The analysis and discussion are shown in the following tables. Single diagram has been provided using MS Excel.

\section{ANALYSIS AND DISCUSSION}

\section{Authorship pattern}

In Table 1, it is seen that the details of the distribution of 425 articles published in the Journal of Poultry Science from January to December' 2001 to 2010 within 39 issues. The maximum number of articles $1^{\text {st }}$ and $2^{\text {nd }} 100(23.53 \%)$ and $97(22.82 \%)$ were published triple and four authors. Single author publication are also poor $22(15.18 \%)$ and the third highest $81(19.06 \%)$ were published more than five authors. It is seem near about fifty percent articles were published were triple and four authors.

67 The Eastern Librarian-peer-reviewed journal in LIS since 1965 
Table 1: Authorship Pattern

\begin{tabular}{|c|c|c|c|c|c|c|c|}
\hline & \multicolumn{6}{|c|}{ Number of Authors } & \\
\hline Years & 1author & 2authors & 3 authors & 4authors & 5authors & $>$ 5authors & Total \\
\hline 2010 & 01 & 04 & 10 & 11 & 11 & 14 & 51 \\
\hline 2009 & 02 & 05 & 07 & 12 & 03 & 13 & 42 \\
\hline 2008 & 02 & 03 & 11 & 10 & 06 & 13 & 45 \\
\hline 2007 & 02 & 08 & 18 & 13 & 10 & 07 & 58 \\
\hline 2006 & 04 & 04 & 13 & 17 & 06 & 09 & 53 \\
\hline 2005 & 01 & 11 & 10 & 08 & 06 & 05 & 41 \\
\hline 2004 & 01 & 06 & 10 & 09 & 05 & 02 & 33 \\
\hline 2003 & 01 & 07 & 09 & 05 & 05 & 05 & 32 \\
\hline 2002 & 05 & 07 & 05 & 08 & 04 & 06 & 35 \\
\hline 2001 & 03 & 09 & 07 & 04 & 05 & 07 & 35 \\
\hline Total & 22 & 64 & 100 & 97 & 61 & 81 & 425 \\
\hline Percentage $(\%)$ & 5.18 & 15.06 & 23.53 & 22.82 & 14.35 & 19.06 & 100 \\
\hline
\end{tabular}

\section{Number of Citations Used by Different Types of Collaborators}

Table 2 shows the detail picture of the authorship pattern of citations. After analysing the above citations 13012 were published of 425 articles JPS, vol. no. 38 to 47 . It is shows most of the citations 3203 (24.62\%) and 2649 (20.36\%) are triple and four authored. More than five and five authored citations amount $1942(14.92 \%)$ and $1738(13.36 \%)$ respectively. 2311(17.26\%) citations are contributed by double authors and only $1169(8.978 \%)$ citations are contributed by single author respectively. Keeping in view the results we can say that in the field of poultry science still combined research predominates.

Table 2: Number of Citations Used by Different Types of Collaborators

\begin{tabular}{|c|c|c|c|c|c|c|c|}
\hline \multirow[b]{2}{*}{ Year } & \multicolumn{6}{|c|}{ Number of Citations } & \multirow[b]{2}{*}{ Total } \\
\hline & 1author & 2authors & 3 authors & 4authors & 5authors & $>$ 5authors & \\
\hline 2010 & 29 & 204 & 416 & 381 & 340 & 359 & 1729 \\
\hline 2009 & 238 & 144 & 218 & 299 & 175 & 369 & 1443 \\
\hline 2008 & 215 & 127 & 296 & 230 & 133 & 364 & 1365 \\
\hline 2007 & 35 & 257 & 639 & 502 & 339 & 149 & 1921 \\
\hline 2006 & 097 & 111 & 549 & 556 & 201 & 178 & 1692 \\
\hline 2005 & 093 & 327 & 204 & 154 & 142 & 095 & 1015 \\
\hline 2004 & 041 & 339 & 194 & 211 & 100 & 046 & 931 \\
\hline 2003 & 054 & 461 & 168 & 081 & 096 & 099 & 959 \\
\hline 2002 & 325 & 140 & 071 & 174 & 120 & 154 & 984 \\
\hline 2001 & 042 & 201 & 448 & 061 & 092 & 129 & 973 \\
\hline Total & 1169 & 2311 & 3203 & 2649 & 1738 & 1942 & 13012 \\
\hline Percentage $(\%)$ & 8.98 & 17.26 & 24.62 & 20.36 & 13.36 & 14.92 & 100 \\
\hline
\end{tabular}




\section{Types of Institutional Affiliation of Contributors}

Table 3 reveals that $278(65.41 \%)$ contributors are affiliated to universities, 69 $(16.24 \%)$ are research institute, and $53(12.47 \%)$ are colleges and only 25 $(5.88 \%)$ belong to other organizations. Hence results have clearly demonstrated that contributors from universities predominate. For table 3 it has considered the first author affiliated to the institutions for analysing purposes.

Table 3: Types of Institutional Affiliation of Contributors.

\begin{tabular}{|c|c|c|c|}
\hline Type of Institutions & Number of Contributors & Percentage(\%) & Cumulative \% \\
\hline Colleges & 53 & 12.47 & - \\
\hline Universities & 278 & 65.41 & 77.88 \\
\hline Research Institutes & 69 & 16.24 & 94.12 \\
\hline Others Organization & 25 & 5.88 & 100 \\
\hline Total & 425 & 100 & - \\
\hline
\end{tabular}

\section{Forms of Citations}

A perusal of table 4 shows that a majority of citations pertain to the journal articles $10972(84.32 \%)$ and $1048(08.06 \%)$ citations are used from books. 523 $(4.02 \%)$ are others and only $340(2.61 \%)$ citations pertain are proceedings, 129 $(0.99 \%)$ citations pertain to reports of information. From this study it is clear that the most of the authors used journals articles. Journal articles can play vital roles for research purposes. So, it can be said that most of the researchers are havily depended on journals articles.

Table 4: Forms of Citations

\begin{tabular}{|c|c|c|c|}
\hline Form of cited Documents & Number of Contributors & Percentage (\%) & Cumulative \% \\
\hline Journals Articles & 10972 & 84.32 & - \\
\hline Books & 1048 & 8.06 & 92.38 \\
\hline Proceedings & 340 & 2.61 & 94.99 \\
\hline Reports & 129 & 0.99 & 95.98 \\
\hline Others & 523 & 4.02 & 100 \\
\hline Total & 13012 & 100 & - \\
\hline
\end{tabular}

69 The Eastern Librarian-peer-reviewed journal in LIS since 1965 


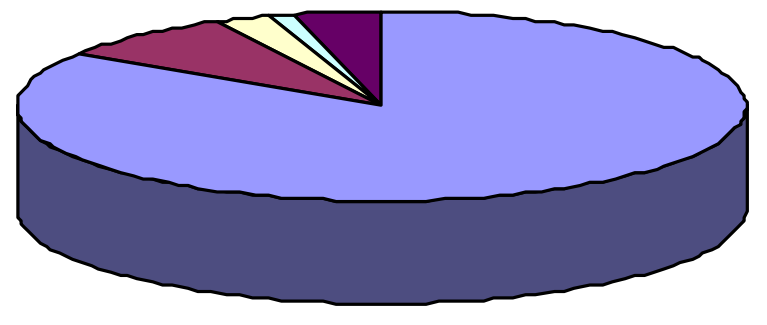

$\square$ Journals articles

Books

Proceedings

Reports

Others

\section{Percentage of Japanese vs. Foreign Contributors}

Table 5 shows an alphabetical list of countries from where the authors contributed the articles to the journal. When an article contributed by more than single authors than first author have been considered for analysing purpose. The table also shows that the $262(61.64 \%)$ articles out of 425 were originated from Japan. This journal is published from Japan. The international contribution of papers $163(38.36 \%)$ from 33 countries and out of which highest papers only $27(6.35 \%)$ were given from USA and nearest India and China are $17(4.00 \%) \& 10(2.35 \%)$.

Table 5: Percentage of Japanese vs. Foreign Contributors

\begin{tabular}{|l|l|c|c|c|}
\hline SI.No & Name of Countries & Contribution & Percentage (\%) & Cumulative \% \\
\hline 01. & Australia & 02 & 0.47 & - \\
\hline 02. & Bangladesh & 08 & 1.88 & 2.35 \\
\hline 03. & Belgium & 02 & 0.47 & 2.82 \\
\hline 04. & Brazil & 03 & 0.70 & 3.52 \\
\hline 05. & Bulgeria & 01 & 0.24 & 3.76 \\
\hline 06. & Canada & 07 & 1.65 & 5.40 \\
\hline 07. & China & 10 & 2.35 & 7.76 \\
\hline 08. & Egypt & 05 & 1.18 & 8.94 \\
\hline 09. & Ethiopia & 01 & 0.24 & 9.18 \\
\hline 10. & Franc & 01 & 0.24 & 9.42 \\
\hline
\end{tabular}

70 The Eastern Librarian-peer-reviewed journal in LIS since 1965 


\begin{tabular}{|l|l|c|c|c|}
\hline 11. & Greece & 01 & 0.24 & 9.66 \\
\hline 12. & Germany & 04 & 0.94 & 10.60 \\
\hline 13. & Hungary & 01 & 0.24 & 10.84 \\
\hline 14. & India & 17 & 4.00 & 14.84 \\
\hline 15. & Indonesia & 03 & 0.70 & 15.54 \\
\hline 16. & Iran & 19 & 4.47 & 20.01 \\
\hline 17. & Israil & 01 & 0.24 & 20.25 \\
\hline 18. & Italy & 01 & 0.24 & 20.49 \\
\hline 19. & Japan & 262 & 61.64 & 82.13 \\
\hline 20. & Jordan & 03 & 0.70 & 82.83 \\
\hline 21. & Lebanon & 04 & 0.94 & 83.77 \\
\hline 22. & Mexico & 02 & 0.47 & 84.24 \\
\hline 23. & Newzealand & 04 & 0.94 & 85.18 \\
\hline 24. & Nigeria & 06 & 1.41 & 86.59 \\
\hline 25. & Pakistan & 03 & 0.70 & 87.29 \\
\hline 26. & Poland & 05 & 1.18 & 88.47 \\
\hline 27. & Portugal & 01 & 0.24 & 88.71 \\
\hline 28. & South Korea & 03 & 0.70 & 89.41 \\
\hline 29. & Sweden & 01 & 0.24 & 89.65 \\
\hline 30. & Taiwan & 02 & 0.47 & 90.12 \\
\hline 31. & Thailand & 05 & 1.18 & 91.30 \\
\hline 32. & Turkey & 04 & 0.94 & 92.24 \\
\hline 33. & UK & 04 & 1.41 & 93.65 \\
\hline 34. & USA & 6.35 & 100 \\
\hline Total & & $\mathbf{4 2 5}$ & & \\
\hline & & & 00 & \\
\hline
\end{tabular}

\section{Ratio of Author Self Citations to Total Citations}

The phenomenon of citing one's own single - authored or multi-authored publications is termed as author self citation. In table 6 reveals that Author Self Citation accounts for only 809 citations. The ratio of Author Self Citation to total citations is 1: 16 . 
Table 6: Ratio of Author Self Citations to Total Citations

\begin{tabular}{|c|c|c|}
\hline Number of author self citations & Total Number of Citations & Ratio \\
\hline 809 & 13012 & $\mathbf{1}: \mathbf{1 6}$ \\
\hline
\end{tabular}

\section{Ratio of Journal Self Citations to Total Citations}

The phenomenon of a journal citing itself is termed as journal self citation. Table 7 indicates that Journal self citation is negligible. The ratio of Journal self citation to total citations is $1: 58$.

Table 7: Ratio of Journal Self Citations to Total Citations

\begin{tabular}{|c|c|c|}
\hline Number of journal self citations & Total Number of Citations & Ratio \\
\hline 223 & 13012 & $1: 58$ \\
\hline
\end{tabular}

\section{Durability of Publications}

In table 8 depicts the major portion of citations $7006(53.84 \%)$ were published from 1987 to 2010 . $10102(77.64 \%)$ citations published below 20 years old. Only 5\% citations were more than 40 years old. It is clear from the result large numbers of citations are taken from recent publications.

Table 8 : Durability of Publications

\begin{tabular}{|c|c|c|c|c|}
\hline 1-10 years & $\mathbf{1 1 - 2 0}$ years & $\mathbf{2 1 - 3 0}$ years & $\mathbf{3 1 - 4 0}$ years & >40 yrs \\
\hline 7006 & 3096 & 1426 & 797 & 687 \\
\hline $53.84 \%$ & $23.79 \%$ & $10.96 \%$ & $6.13 \%$ & $5.28 \%$ \\
\hline
\end{tabular}

\section{FINDINGS}

The following are the major finding observed from the study:

i) The international exposure $163(38.36 \%)$ to this Journal are very high, 33 countries contribute the JPS in vol. $38-47$.

ii) Each articles were published with cited references, it shows that only the research articles are published. The average number of cited references is 30.

iii) The average number of articles published is each issue is 11 .

iv) The large of cited reference are recent publication.

72 The Eastern Librarian-peer-reviewed journal in LIS since 1965 
v) Journal self citation is negligible (only 223 out of 13012), which reflects that the journal does not command high respect even among Japanese Poultry Scientists as well.

vi) Number of author self citations is high (809 out of 13012). It is observed the large number of authors practices before this study.

vii) Highest number of citations are taken from journal source i.e. 10972 $(84.32 \%)$ and next are from books 1048 (8.06\%).

viii) It is concluded from the authorship pattern study that the maximum articles ( $91 \%$ ) has been cited (written) more than single author.

ix) Most of the articles comes from educational institute.

\section{REFERENCES}

Hirade, M.A. \& Dankhade, S.S.K. (2002). Citation analysis of Doctoral research in Economics. ILA Bulletin, 38(2), 36 - 45

Weiping Yue, S., Concepion \& Wilson (2004). Measuring the citation impact of research journals in clinical neurology : A structural equation modeling analysis. Scientometrics 60 (3), 317-332.

Locket, B. (1989). Guide to the evaluation of library collections, Chicago : American Library Association.

Baskaram, C., Batcha, M.S. \& Nagarajan, M. (2007). Citation impact and pattern of co-authorship of cardiology journals in G8 countries. 1(1).

Wilson, C.S (1999). Informatics. Annual Review of Information Science and Technology 34. p 107-242

Jan, R. (2009). Citation analysis of Library Trends. Webology, 6(1). Retrieved from http://www.webology.org/2009/v621/167.html

Shokeen, A. \& Kaushik, S.K. (2004). Indian Journal of Plant Physiology : A Citation Analysis. Annals of Library and Information Studies. 51(3).104-107.

73 The Eastern Librarian-peer-reviewed journal in LIS since 1965 